\title{
The Contribution of Different Spectral Sections to Increase Fresh Weight of Boston Lettuce
}

\author{
Shih-Wei Kong and Hsin-Ying Chung \\ Department of Bio-Industrial Mechatronics Engineering, National Taiwan \\ University, No. 1, Section 4, Roosevelt Road, Taipei, Taiwan, 106, Republic \\ of China
}

\begin{abstract}
Ming-Yi Chang
Department of Biomechatronic Engineering, National Ilan University, No. 1, Section 1, Shen-Lung Road, I-Lan, Taiwan, 260, Republic of China
\end{abstract}

\author{
Wei Fang ${ }^{1}$ \\ Department of Bio-Industrial Mechatronics Engineering, National Taiwan \\ University, No. 1, Section 4, Roosevelt Road, Taipei, Taiwan, 106, Republic \\ of China
}

Additional index words. spectrum, boston lettuce, fresh weight, growth model, artificial light

\begin{abstract}
Six types of light sources [0G, 20G, 40G, cool-white light-emitting diode (LED CW), cool-white fluorescent lamp (FLCW), and plant light fluorescent lamp (TLRA)] were used as the sole light sources to cultivate boston lettuce (Lactuca sativa $\mathrm{L}$. cv. Ostinata). The photosynthetically active radiation $(P A R)$ range was separated into five sections and the contributions of each spectral section on fresh weight (FW) were quantified. The results indicate that the conventional method of separating $P A R$ into red, green, and blue at $100 \mathrm{~nm}$ apart was not accurate enough to clarify the contribution of different spectral sections to FW of boston lettuce. Green light $(525-575 \mathrm{~nm})$ at less than $30 \%$ of $P A R$ is even more important than red $(625-700 \mathrm{~nm})$ and blue $(400-475 \mathrm{~nm})$ to plant growth. Yellow light $(575-625 \mathrm{~nm})$ has very little effect on plant growth.
\end{abstract}

Light plays an important role in photosynthesis. Visible light is defined in the wavelength from 380 to $780 \mathrm{~nm}$. Light within 400 to $700 \mathrm{~nm}$, termed $P A R$, can be roughly separated into blue $(\mathrm{B}, 400-500 \mathrm{~nm})$, green $(\mathrm{G}, 500-600 \mathrm{~nm})$, and red (R, 600-700 nm). RGB light affects plant growth in different ways. For example, blue light induces biomass production but suppresses the hypocotyl elongation; red light boosts hypocotyl elongation and expands leaf (Johkan et al., 2010; McNellis and Deng, 1995). As for green light, researchers (Folta, 2004; Kim et al., 2004a, 2004b) found that it is related to leaf growth, stomatal conductance, and early stem extension. Green light is considered to be insignificant in driving photosynthesis due to the low absorptivity coefficient in the absorption spectra of purified chlorophylls (Sun et al., 1998).

Light-emitting diodes (LEDs) allow production of light that emit only the wavelengths of light corresponding to the absorption peaks of plant requirements. Other advantages such as energy efficiency, long lifetime, low heat generated at the side-facing plants, and dramatic decrease of cost make them popular light sources to enhance plant growth, increase

Received for publication 8 May 2014. Accepted for publication 14 Oct. 2014.

${ }^{1}$ To whom reprint requests should be addressed; e-mailweifang@ntu.edu.tw. green LEDs (20G: relative peaks at 462,525 , and $660 \mathrm{~nm}$ ), and $40 \%$ green LEDs (40G: relative peaks at 462,525 , and $640 \mathrm{~nm}$ ). Another three were commercially available. They were $6500 \mathrm{~K}$ LED CW (relative peaks at 447 and $569 \mathrm{~nm}$, Wellypower, Taiwan), $6500 \mathrm{~K} \mathrm{FLCW}$ (relative peaks at 436, 546, and $611 \mathrm{~nm}$, Wellypower), and TLRA (relative peaks at 436, 546, 611, and $660 \mathrm{~nm}$, Wellypower). The ratio of blue light was between $20 \%$ and $26 \%$ in $0 \mathrm{G}, 20 \mathrm{G}$, and $40 \mathrm{G}$. Photosynthetic photon flux $(P P F)$ of all treatments was adjusted to $150 \mu \mathrm{mol} \cdot \mathrm{m}^{-2} \cdot \mathrm{s}^{-1}$ measured with quantum meter (Quantum sensor Q46758 and LI-250A; LI-COR, USA) in a distance of $25 \mathrm{~cm}$ under light sources, and 96 points $(16 \times 6)$ were measured to calculate the mean and standard deviation values of $P P F$ on the surface of a culture tray $(120 \times$ $60 \mathrm{~cm}$ ). All Spectra were measured using Spectrometer (USB 4000; Ocean Optics, USA) in a distance of $25 \mathrm{~cm}$ under light sources (Fig. 1).

Plant material and growth conditions. Lettuce (L. sativa L. cv. Ostinata; KnownYou Seed Co., Taiwan) was cultured hydroponically using the deep flow technique (DFT) in an environmental-controlled confined chamber $\left(5 \mathrm{~m}^{2}\right)$ of ILan University. Lettuce seeds were soaked for $5 \mathrm{~h}$ then sown into plug trays, using foam/sponge cube as growth media, and allowing germination and growth for $6 \mathrm{~d}$ (stage 1) under $6500 \mathrm{~K}$ LED $\mathrm{CW}$ with $P P F$ at 100 $\mu \mathrm{mol} \cdot \mathrm{m}^{-2} \cdot \mathrm{s}^{-1}$ in a growth chamber. The temperature and humidity of the chamber were kept at $20^{\circ} \mathrm{C}$ and $70 \%$ to $80 \%$ with a 24 -h light period. In stage 2 , the seedlings were transplanted to another room with temperature of $25^{\circ} \mathrm{C}$ day $/ 18{ }^{\circ} \mathrm{C}$ night and humidity of $70 \%$ to $80 \%$ and provided with various light sources (0G, 20G, 40G, LED CW, FLCW, and TLRA) with daily light integral (DLI) of 8.64 $\mathrm{mol} \cdot \mathrm{m}^{-2} \cdot \mathrm{d}^{-1}\left(16 \mathrm{~h} \cdot \mathrm{d}^{-1} \times 150 \mu \mathrm{mol} \cdot \mathrm{m}^{-2} \cdot \mathrm{s}^{-1}\right)$. The $\mathrm{CO}_{2}$ concentration was kept at $1200 \mathrm{ppm}$ in light period. The soluble complex nutrient solution (Type 1, 7N-6P-19K; Hyponex) was used and the $\mathrm{pH}$ and electrical conductivity (EC) were maintained at 6 and $1.2 \mathrm{mS} \cdot \mathrm{cm}^{-1}$ (1.03 g. $\left.\mathrm{L}^{-1}\right)$, respectively.

Plant densities were 180 plants $/ \mathrm{m}^{2}$ from days 7 to 17 , and 40 plants $/ \mathrm{m}^{2}$ from days 18 to 39. All plants were harvested on the 39th day after seeding. The roots and shoots were separated and FW was measured. The shoots were dried for $3 \mathrm{~d}$ at $75^{\circ} \mathrm{C}$ to determine dry weight (DW).

Model description. Albright et al. (1999) developed a vegetative growth model of boston lettuce based on environmental conditions, including air temperature, $\mathrm{CO}_{2}$ concentration, light integral, and nitrate concentration of the nutrient solution. As shown below, coefficient " $A$," in Eqs. [1] and [2], was the environmental coefficient related to the integrated $P P F(L)$ during cultivation, and indoor $\mathrm{CO}_{2}$ concentration $(C)$. Parameter " $d$ " represented the growth day from seeding, and " $\exp \left(C_{1} d-C_{2} d^{2}\right)$ " was normalized growth curve of DW. With the given " $A$ " and " $d$," the DW at day $d\left(\mathrm{DW}_{d}\right)$ can be derived.

$$
\begin{aligned}
\mathrm{DW}_{d}=A \exp \left(C_{1} d-C_{2} d^{2}\right) \\
A=1.14 \times 10^{-5}+9.57 \times 10^{-6} L \\
+7.67 \times 10^{-8} C
\end{aligned}
$$
Eq. [3] as shown below:
Eqs. [1] and [2] can be combined to form 

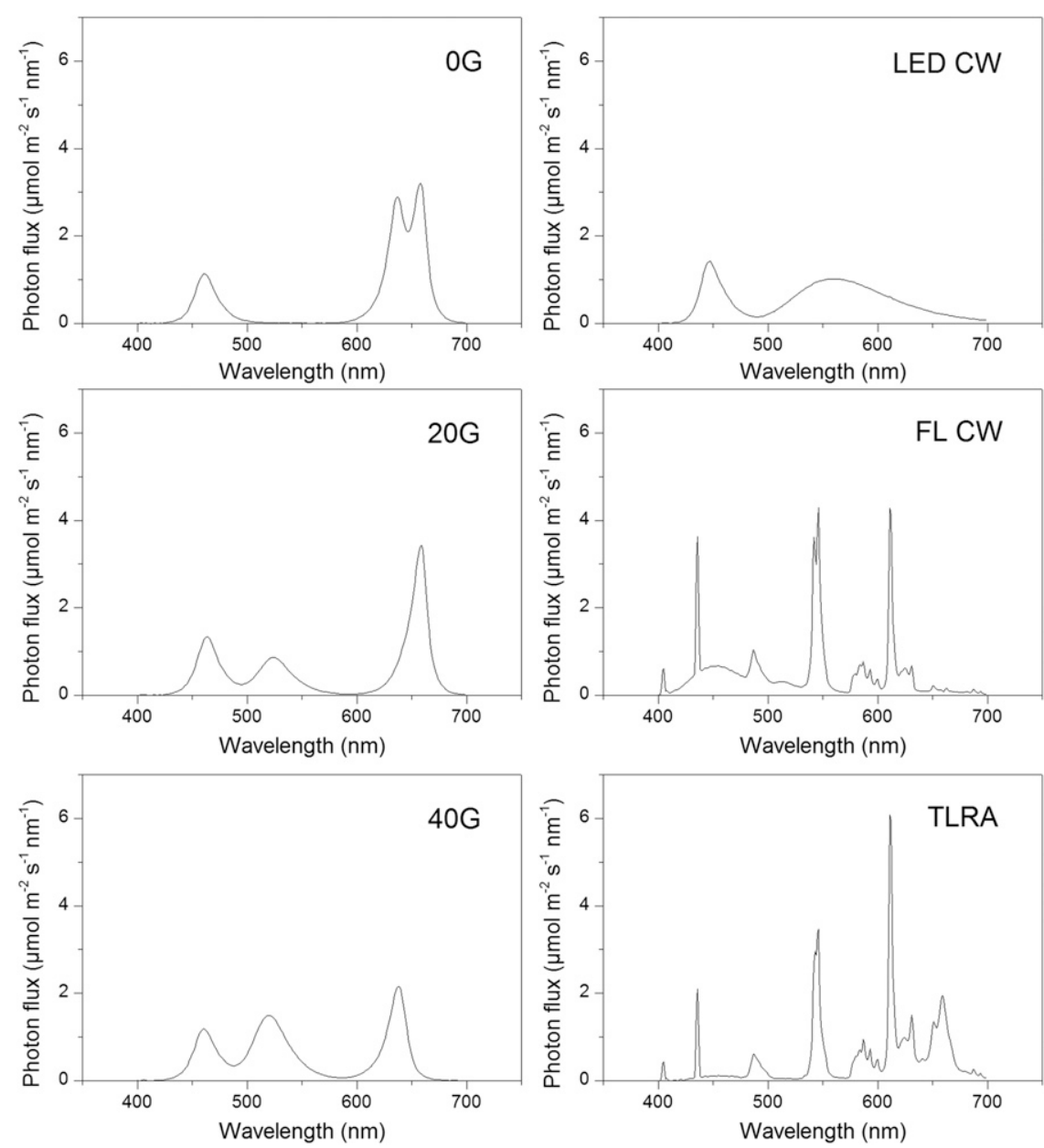

Fig. 1. Spectral distribution of light from red and blue light-emitting diodes (LEDs) (0G), red and blue LEDs mixed with $20 \%$ green (20G), $40 \%$ green LEDs light (40G), $6500 \mathrm{~K}$ cool-white LEDs (LED $\mathrm{CW}$ ), $6500 \mathrm{~K}$ cool-white fluorescent lamps (FLCW), and plant light fluorescent lamps (TLRA).

$$
\begin{aligned}
\mathrm{DW}_{d}= & \left(A_{1}+A_{2} L+A_{3} C\right) \\
& \times \exp \left(C_{1} d-C_{2} d^{2}\right)
\end{aligned}
$$

$A_{1}, A_{2}$, and $A_{3}$ are constant and weighing coefficient of integrated $P P F(L)$ and $\mathrm{CO}_{2}$ concentration $(C) . C_{1}$ and $C_{2}$ were 0.5712 and 0.007742 , respectively, according to Albright et al. (1999).

In this study, $\mathrm{CO}_{2}$ concentration was fixed, the term $A_{3} C$ becomes constant and can be merged with the term $A_{1}$ expressed in $A_{1}^{\prime}$. To analyze the effect of different spectral sections on plants growth, the $P P F$ waveband was separated into various partitions, and each partition represents a specific range of wavelength. Eq. [3] could be modified as shown below:

$$
\begin{aligned}
\mathrm{DW}_{d}= & \left(A_{1}^{\prime}+\sum_{i=1}^{n}\left(B_{i} W_{i}\right)\right) \\
& \times \exp \left(C_{1} d-C_{2} d^{2}\right)
\end{aligned}
$$

where $W_{i}$ is the integrated $P P F$ of separated spectral section, and $B_{i}$, the weighing factor of $W_{i}$, represents the contribution of related spectral range.

From the commercial point of view, the market price of lettuce was measured based on FW, Eq. [5] was derived.

$$
\begin{aligned}
\mathrm{FW}_{d}= & \left(A_{1}^{\prime}+\sum_{i=1}^{n}\left(B_{i} W_{i}\right)\right) \\
& \times \exp \left(C_{1}^{\prime} d-C_{2}^{\prime} d^{2}\right) \\
& C_{1}^{\prime}: 0.1145 \\
& C_{2}^{\prime}:-0.001602
\end{aligned}
$$

$\mathrm{FW}_{d}$ is the fresh weight at day $d$ and " $\exp \left(C_{1}^{\prime} d-C_{2}^{\prime} d^{2}\right) "$ is the normalized growth curve of FW $\left(R^{2}: 0.9987\right)$ calculated from FW of boston lettuce from day 14 to day 35 (Wang, 2010).

A dramatic difference can be found in the coefficient of $d^{2}$ term. This term is highly related to the latter growth of lettuce due to value of days after seeding $(d)$ was squared. The positive value of $C_{2}$ indicates that the growth rate of lettuce, expressed in terms of the value of DW and FW, was decreasing, that is approaching saturation, when $d$ value gets bigger. However, the negative value of $C_{2}^{\prime}$ indicates that the mass of lettuce will continue to increase without saturation. This is one of the major differences between plant growth under sunlight and under artificial light. When grown under sunlight, in the same weather conditions, the amount of $P P F$ will not vary too much whether the lettuce was young or matured. However, in a plant growth chamber using artificial light, the bigger the plant growth and the closer it gets to the light source, the more $P P F$ it gets. It did not reach saturation within the experimental conditions of this study.

Number of spectral sections. Chlorophyll $a$ and $b$ were the primary phytochemical compounds. These compounds had highest absorption efficiency at 430, 453, 642, and $662 \mathrm{~nm}$ (Gross, 1991). There were other light-harvesting pigments, such as carotenoids, which absorbed light with the highest efficiency at $450 \mathrm{~nm}$ (Vierstra and Poff, 1981). To take account the peak wavelength of light sources and the highest absorption wavelength of photo pigments of plant, allowing all peak wavelengths within the middle of each sections as much as possible, the $P A R$ range of 400 to $700 \mathrm{~nm}$ was unevenly divided into five sections: $400-475,475-525$, $525-575,575-625$, and $625-700 \mathrm{~nm}$. To compare with previous studies, the data were also analyzed in a traditional way, which separated the $P A R$ range into $\mathrm{R}(600-700 \mathrm{~nm}), \mathrm{G}(500-600 \mathrm{~nm})$, and B (400-500 nm) sections.

Statistical analysis. Each treatment $(0 \mathrm{G}$, 20G, 40G, LED CW, FLCW, and TLRA) was harvested in 15 plants for statistical analysis. Using $5 \%$ as the level of significance, statistical analysis was subjected to analysis of variance followed by Duncan's multiple range tests (SPSS, IBM). To obtain the indexes about the effect caused by different wavebands, $B_{i}$ in Eq. [5] has been determined by Levenberg-Marquardt algorithm using commercially available software (1stOpt; 7D-Soft High Technology, China).

\section{Results and Discussion}

As shown in Table 1, a total of four LED and two fluorescent light (FL) sources were used. The LEDs performed significantly better than FLs in terms of FW and DW. The treatment $20 \mathrm{G}(23 \%$ green as shown in Table 2) has the greatest mean FW. However, it shows no significant difference with other LED light sources including less green $(0 \mathrm{G})$, more green (40G), and LED CW (51\% green).

The DW of $20 \mathrm{G}$ was the lowest compared with $0 \mathrm{G}$ and $40 \mathrm{G}$. The water content of $20 \mathrm{G}$ $(97.72 \%)$ was significantly higher than $0 \mathrm{G}$ $(96.86 \%)$ and $40 \mathrm{G}(97.11 \%)$. The reason might be the difference on the peak wavelength of red light. The red peak of $20 \mathrm{G}$ was $660 \mathrm{~nm}$, but $0 \mathrm{G}$ was 640 and $660 \mathrm{~nm}$, and $40 \mathrm{G}$ was $640 \mathrm{~nm}$. The $R_{660} / R_{640}$ ratios of 20G, $0 \mathrm{G}$, and $40 \mathrm{G}$ were $3.29,1.07$, and 0.08 as shown in column 3 of Table 1 . The same result can be derived for fluorescent lamps, the $R_{660} / R_{640}$ ratios of FLCW (1.23) and TLRA (3.37) are close to $20 \mathrm{G}$ (3.29), thus leading to no significant difference on water content among these three treatments. The higher $R_{660} / R_{640}$ ratio might reduce the $\mathrm{DW}$ and increase water content at the condition of 
the same FW. This hypothesis requires further investigation.

FLCW lamps are often used for plant cultivation, but the results showed that the FW of lettuce under FLCW was significantly lower than other treatments.

The proposed model was used by separating $P A R$ range into three and five sections as mentioned above. The $R^{2}$ values were 0.15 and 0.92 , respectively (Tables 2 and 3 ). The dramatic difference on $R^{2}$ suggested that the conventional RGB model was not accurate enough to clarify the contribution of different spectral sections to FW of boston lettuce.

In plant physiology, blue light suppressed hypocotyl elongation, induced biomass production, and affected stomatal conductance $\left(g_{\mathrm{S}}\right)$. Red light induced hypocotyl elongation and expansion in leaf area (Johkan et al., 2010; McNellis and Deng, 1995). Green light also affected leaf growth, $g_{\mathrm{S}}$, and early stem elongation (Folta, 2004; Kim et al., 2004a, 2004b).

As shown in Table 3, the data shown in the second row from the bottom entitled "contributions" indicated that almost all spectral sections had contributions to the increase of lettuce FW except for the section of yellow light $(575-625 \mathrm{~nm})$. The bottom row shows that relative contributions of blue (400-475 nm), blue-green (475-525 $\mathrm{nm})$, green $(525-575 \mathrm{~nm})$, yellow $(575-625$ $\mathrm{nm})$, and red $(625-700 \mathrm{~nm})$ sections were $23.62,15.34,100,0$, and 56.3, respectively. The range of the green section was the smallest ( 50 vs. $75 \mathrm{~nm}$ of red and blue), yet it has the most profound impact on growth under the given light source within its maximum and minimum range as shown in Fig. 2.

Further analysis focusing on lights with high green ratio was conducted based on the results derived from Table 3. Spectrum data of the yellow section and growth data using $0 \mathrm{G}$ and $20 \mathrm{G}$ LEDs were ignored. As shown in Table 4, there are four types of light sources: two LEDs and two FLs (40G, LED $\mathrm{CW}, \mathrm{FL}$ CW, and TLRA) with the green ratio of $18.8 \%$ to $30.7 \%$. The results shown in Table 4 indicate that the relative contributions of red (69.21) and blue (85.09) were higher than data shown in Table 3. This showed that the contribution of green light was decreased when the intensity of green light increased in the range of $0 \%$ to $30 \%$ of $P A R$. Column 3 of Table 4 also indicates that the range of blue-green $(475-525 \mathrm{~nm})$ has no impact on FW accumulation of lettuce under conditions of green light at $18 \%$ to $30 \%$ of $P A R$.

Green light was often assumed to be unimportant in driving photosynthesis mainly due to the low absorptivity in the absorption spectra of purified chlorophylls (Sun et al., 1998). In a spectrophotometer cuvette containing dissolved chlorophyll, the internal reflection did not occur, so the absorption of green light was considered to be very low (Salisbury and Ross, 1992). Although the chances of green wavelengths
Table 1. $P P F$, shoot $\mathrm{FW}, \mathrm{DW}$, and percentage of water of lettuce grown under six light sources.

\begin{tabular}{|c|c|c|c|c|c|}
\hline \multirow[b]{2}{*}{ Type of lights } & \multirow[b]{2}{*}{$P P F\left(\mu \mathrm{mol} \cdot \mathrm{m}^{-2} \cdot \mathrm{s}^{-1}\right)$} & \multirow[b]{2}{*}{$R_{660} / R_{640}{ }^{2}$} & \multicolumn{3}{|c|}{ Parameter $^{y}$} \\
\hline & & & FW (g) & DW (g) & Water (\%) \\
\hline$\overline{0 \mathrm{G}}$ & $149.56 \pm 24.89$ & 1.07 & $85.40 \mathrm{ab}$ & $2.58 \mathrm{ab}$ & $96.86 \mathrm{bc}$ \\
\hline $20 \mathrm{G}$ & $149.11 \pm 24.37$ & 3.29 & $90.94 \mathrm{a}$ & $2.08 \mathrm{~cd}$ & $97.72 \mathrm{a}$ \\
\hline 40G & $150.87 \pm 23.75$ & 0.08 & $83.26 \mathrm{ab}$ & $2.42 \mathrm{abc}$ & $97.11 \mathrm{bc}$ \\
\hline LED CW & $147.76 \pm 18.66$ & 0.64 & $87.01 \mathrm{ab}$ & $2.77 \mathrm{a}$ & $96.80 \mathrm{c}$ \\
\hline FLCW & $147.46 \pm 12.49$ & 1.23 & $72.21 \mathrm{c}$ & $1.96 \mathrm{~d}$ & $97.33 \mathrm{ab}$ \\
\hline TLRA & $150.15 \pm 21.70$ & 3.37 & $78.33 \mathrm{bc}$ & $2.20 \mathrm{bcd}$ & $97.29 \mathrm{ab}$ \\
\hline
\end{tabular}

${ }^{\mathrm{z}}$ The ranges for $R_{640}$ and $R_{660}$ were $635-645 \mathrm{~nm}$ and $655-665 \mathrm{~nm}$.

${ }^{y}$ Means followed by different letters in three columns were significantly different at $5 \%$ level by Duncan's multiple range test.

$\mathrm{DW}=$ dry weight $\mathrm{FW}=$ fresh weight LED CW $=$ cool-white light-emitting diode; FLCW $=$ cool-white fluorescent lamp; $P P F=$ photosynthetic photon flux; TLRA = plant light fluorescent lamp.

Table 2. Contribution of equally distributed three spectral sections within photosynthetically active radiation $(400-700 \mathrm{~nm}$ ) range to the harvested shoot $\mathrm{FW}$ of boston lettuce at day 39 after seeding under six light sources.

\begin{tabular}{lcccc}
\hline & \multicolumn{3}{c}{ Range } \\
\cline { 2 - 4 } Types of light & $400-500$ & $500-600$ & $600-700$ & \\
\cline { 2 - 4 } 0G & $100 \mathrm{~nm}$ & $100 \mathrm{~nm}$ & $100 \mathrm{~nm}$ & FW (g) \\
20G & $21(\%)$ & 0 & 79 & 85.40 \\
40G & 26 & 23 & 51 & 90.94 \\
LED CW & 26 & 40 & 34 & 83.26 \\
FLCW & 28 & 51 & 21 & 87.01 \\
TLRA & 36 & 40 & 23 & 72.21 \\
& 12 & 30 & 58 & 78.33 \\
Calculated results & & & & $R^{2}$ \\
Contributions & $\mathrm{B}_{1}$ & $\mathrm{~B}_{2}$ & $\mathrm{~B}_{3}$ & 0.15 \\
Relative contributions & $9.549 \mathrm{E}-03$ & $9.204 \mathrm{E}-03$ & $1.014 \mathrm{E}-02$ & \\
\hline & 103.75 & 100.00 & 110.21 & \\
\hline
\end{tabular}

$\mathrm{FW}=$ fresh weight; LED CW = cool-white light-emitting diode; FLCW = cool-white fluorescent lamp; TLRA $=$ plant light fluorescent lamp.

Table 3. Contribution of five unequally distributed spectral sections within photosynthetically active radiation $(400-700 \mathrm{~nm})$ range to the harvested shoot $\mathrm{FW}$ of boston lettuce at day 39 after seeding under six light sources.

\begin{tabular}{lcccccc}
\hline & \multicolumn{5}{c}{ Range } & \\
\cline { 2 - 6 } & $400-475$ & $475-525$ & $525-575$ & $575-625$ & $625-700$ & \\
\cline { 2 - 6 } Types of light & $75 \mathrm{~nm}$ & $50 \mathrm{~nm}$ & $50 \mathrm{~nm}$ & $50 \mathrm{~nm}$ & $75 \mathrm{~nm}$ & FW (g) \\
\hline 0G & $16.0(\%)$ & 3.95 & 0.26 & 7.70 & 72.1 & 85.40 \\
20G & 18.6 & 15.8 & 12.3 & 2.16 & 51.1 & 90.94 \\
40G & 18.1 & 26.3 & 18.8 & 7.57 & 29.2 & 83.26 \\
LED CW & 24.2 & 9.41 & 30.7 & 24.3 & 11.4 & 87.01 \\
FLCW & 25.4 & 14.8 & 27.5 & 24.6 & 7.71 & 72.21 \\
TLRA & 6.73 & 5.72 & 20.1 & 32.9 & 34.6 & 78.33 \\
& & & & & & \\
Calculated results & $\mathrm{B}_{1}$ & $\mathrm{~B}_{2}$ & $\mathrm{~B}_{3}$ & $\mathrm{~B}_{4}$ & $\mathrm{~B}_{5}$ & $R^{2}$ \\
Contributions & $5.22 \mathrm{E}-03$ & $3.39 \mathrm{E}-03$ & $2.21 \mathrm{E}-02$ & $1.52 \mathrm{E}-16$ & $1.24 \mathrm{E}-02$ & 0.92 \\
Relative contributions & 23.62 & 15.34 & 100.00 & 0.00 & 56.30 & \\
\hline FW
\end{tabular}

$\mathrm{FW}=$ fresh weight; $\mathrm{LED} \mathrm{CW}=$ cool-white light-emitting diode; FLCW $=$ cool-white fluorescent lamp; TLRA $=$ plant light fluorescent lamp.

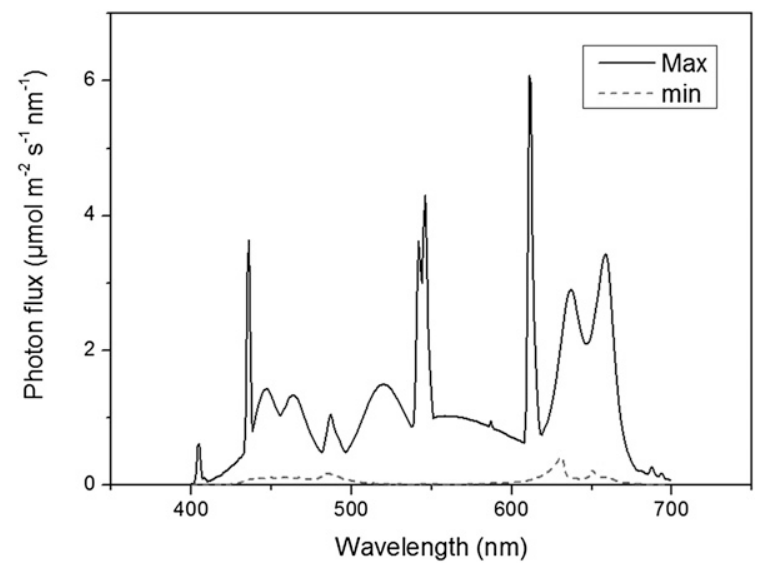

Fig. 2. Maximum and minimum intensity of spectral distribution of six light sources used in this study (0G, 20G, 40G, cool-white light-emitting diode, cool-white fluorescent lamp, and plant light fluorescent lamp). 
Table 4. Contribution of five unequally distributed spectral sections within photosynthetically active radiation $(400-700 \mathrm{~nm})$ range to the harvested shoot $\mathrm{FW}$ of boston lettuce at day 39 after seeding under four light sources.

\begin{tabular}{lcccccc}
\hline & \multicolumn{5}{c}{ Range } & \\
\cline { 2 - 6 } Types of light & $400-475$ & $475-525$ & $525-575$ & $575-625$ & $625-700$ & FW (g) \\
\cline { 2 - 6 } 40G & $75 \mathrm{~nm}$ & $50 \mathrm{~nm}$ & $50 \mathrm{~nm}$ & $50 \mathrm{~nm}$ & $75 \mathrm{~nm}$ & 83.26 \\
LED CW & $18.1(\%)$ & 26.3 & 18.8 & 7.57 & 29.2 & 87.01 \\
FLCW & 24.2 & 9.41 & 30.7 & 24.3 & 11.4 & 72.21 \\
TLRA & 25.4 & 14.8 & 27.5 & 24.6 & 7.71 & 78.33 \\
& 6.73 & 5.72 & 20.1 & 32.9 & 34.6 & \\
Calculated results & $\mathrm{B}_{1}$ & $\mathrm{~B}_{2}$ & $\mathrm{~B}_{3}$ & & $\mathrm{~B}_{5}$ & $R^{2}$ \\
Contributions & $1.19 \mathrm{E}-02$ & $2.15 \mathrm{E}-16$ & $1.71 \mathrm{E}-02$ & & $1.46 \mathrm{E}-02$ & 0.99 \\
Relative contributions & 69.21 & 0.00 & 100.00 & & 85.09 & \\
\hline FW
\end{tabular}

FW = fresh weight; LED CW = cool-white light-emitting diode; FLCW = cool-white fluorescent lamp; TLRA = plant light fluorescent lamp.

being absorbed by chlorophylls were small, the wavelengths that were not absorbed would be repeatedly reflected from chloroplast to chloroplast between the photosynthetic cells. With each reflection, a small percentage of the energy was absorbed until half or more was absorbed and used in photosynthesis (Kim et al., 2006). In addition, the active spectra for photosynthesis showed that green light was in an effective spectral region to power up photosynthesis in higher plants (McCree, 1972). In thylakoids, most of the carotenoids could efficiently transfer their excitation energy to the same reaction centers like chlorophylls, so they also contributed to photosynthesis (Siefermann-Harms, 1987; Taiz and Zeiger, 1991).

Kim et al. (2004a, 2004b) reported that lettuce showed better growth and higher photosynthetic rates with the addition of $5 \%$ supplemental green light $(500-600 \mathrm{~nm})$ compared with only using the red (600$700 \mathrm{~nm})$ and blue $(400-500 \mathrm{~nm})$ LEDs, and the addition of $24 \%$ green light (500$600 \mathrm{~nm}$ ) could positively enhance plant growth. Leaves in the lower canopy would be able to use the transmitted green light in photosynthesis and perhaps reduce levels of leaf senescence and/or shedding within the canopy (Preece and Read, 1993). Green light was effectively absorbed by green leaves, and efficiently drove electron transport (Sun et al., 1998). Terashima et al. (2009) indicated that green light mixed with strong white light drove photosynthesis more effectively than red light in sunflower leaves.

The contribution indexes of different spectral sections to the growth of lettuce $\left(B_{i}\right)$ are shown in Table 3 . It was a combination of effects related to plant photosynthesis, leaf transmittance, $g_{\mathrm{S}}$, and carbon fixation. The index of spectral section from 575 to $625 \mathrm{~nm}$ was $1.52 \mathrm{E}-16$, which indicated that this portion of wavelength made no contribution to FW of lettuce.

Researchers categorized wavelengths from 500 to $600 \mathrm{~nm}$ as "green" light and concluded that additional green light promotes plant growth. This study further clarified that green light only within the range of 525 to $575 \mathrm{~nm}$ promotes plant growth.
Dougher and Bugbee (2001) suggested that "yellow" light from 580 to $600 \mathrm{~nm}$ suppressed chlorophyll or chloroplast formation. In Euglena, Schwartzbach (1990) determined that "green" light (peak at 597 $\mathrm{nm}$ ) was less effective than blue in the saturating. Al-Wakeel and Hamed (1996) showed more growth suppression under "yellow" (peak at $595 \mathrm{~nm}$ ) than "green" (peak at $520 \mathrm{~nm}$ ) light in cucumbers. This study had consistent results and agreed with these studies.

The proposed model only considered the effect of single spectral section on lettuce and it did not consider the effect of interaction between spectra sections. For example, adjusting the ratio of blue and green light could stimulate the stomatal opening (Frechilla et al., 2000; Kim et al., 2004a; Talbott et al., 2002) and Emerson enhancement effect involved far red light (Govindjee, 1964). Therefore, this model can only be used to analyze spectrum of light sources within the minimum and maximum ranges as shown in Fig. 2. Nevertheless, optimum light spectral design can be derived from such models with further investigation.

\section{Conclusions}

A model was proposed to investigate the effects of various spectral ranges on the growth of plants in terms of FW and/or DW. Boston lettuce was used as the example. The low $R^{2}$ value suggested that the traditional analytical method which separated $P A R$ range into $\mathrm{R}, \mathrm{G}$, and $\mathrm{B}$ sections was somehow misleading. This study separated the same range into five sections and revealed that the green light $(525-575 \mathrm{~nm})$ has much higher contribution than red (625$700 \mathrm{~nm})$ and blue $(400-475 \mathrm{~nm})$. The researchers categorized wavelengths from 500 to $600 \mathrm{~nm}$ as "green" light and concluded that additional green light promotes plant growth. This study further clarified that "green" only within the range of 525 to $575 \mathrm{~nm}$ promotes plant growth. "Greenyellow" range from 575 to $625 \mathrm{~nm}$ has relatively very little effect on the growth of boston lettuce. synthesis of chlorophyll when light was

\section{Literature Cited}

Albright, L.D., A.J. Both, R.W. Langhans, and E.F. Wheeler. 1999. Dimensionless growth curves as a simple approach to predict the vegetative growth of lettuce. Acta Hort. 507:293-300.

Al-Wakeel, S.A.M. and A.A. Hamed. 1996. Lightquality effect on growth and some biochemical aspects of mild-stressed Cucurbita pepo L. Egyptian J. 36:217-233.

Dougher, T.A.O. and B. Bugbee. 2001. Evidence for yellow light suppression of lettuce growth. Photochem. Photobiol. 73:208-212.

Fan, X.X., Z.G. Xu, X.Y. Liu, C.M. Tang, L.W Wang, and X.L. Han. 2013. Effects of light intensity on the growth and leaf development of young tomato plants grown under a combination of red and blue light. Sci. Hort. 153:50-55.

Folta, K.M. 2004. Green light stimulates early stem elongation, antagonizing lightmediated growth inhibition. Plant Physiol. 135:1407-1416.

Frechilla, S., L.D. Talbott, R.A. Bogomolni, and E. Zeiger. 2000. Reversal of blue light-stimulated stomatal opening by green light. Plant Cell Physiol. 41:171-176.

Govindjee, R. 1964. Emerson enhancement effect in chloroplast reactions. Plant Physiol. 39: 10 .

Gross, J. 1991. Pigments in vegetables: Chlorophylls and carotenoids. Van Nostrand Reinhold, ISBN 0442006578.

Islam, M.A., D. Tarkowská, J.L. Clarke, D. Blystad, H.R. Gislerød, S. Torre, and J.E. Olsena. 2014. Impact of end-of-day red and far-red light on plant morphology and hormone physiology of poinsettia. Sci. Hort. 174:77-86.

Jao, R.C. and W. Fang. 2004. Effects of frequency and duty ratio on the growth of potato plantlets in vitro using LEDs. HortScience 39:375-379.

Johkan, M., K. Shoji, F. Goto, S. Hashida, and T. Yoshihara. 2010. Blue light-emitting diode light irradiation of seedlings improves seedling quality and growth after transplanting in red leaf lettuce. HortScience 45:1809-1814.

Kim, H.H., G.D. Goins, R.M. Wheeler, and J.C. Sager. 2004a. Green-light supplementation for enhanced lettuce growth under red-and bluelight-emitting diodes. HortScience 39:16171622 .

Kim, H.H., R.M. Wheeler, Kim, J.C. Sager, and G.D. Gains. 2004b. A comparison of growth and photosynthetic characteristics of lettuce grown under red and blue light-emitting diodes (LEDs) with and without supplemental green LEDs. Acta Hort. 659:467-475.

Kim, H.H., R.M. Wheeler, and J.C. Sager. 2006. Evaluation of lettuce growth using supplemental green light with red and blue light-emitting diodes in a controlled environment: A review of research at Kennedy Space Center. Acta Hort. 711:111-119.

McCree, K.J. 1972. The action spectrum, absorptance and quantum yield of photosynthesis in crop plants. Agr. Meteorol. 9:191-216.

McNellis, T.W. and X.W. Deng. 1995. Light control of seedling morphogenetic pattern. Plant Cell 7:1749-1761.

Preece, J.E. and P.E. Read. 1993. The biology of horticulture: An introductory textbook. John Wiley \& Sons, Inc., New York, NY.

Salisbury, F.B. and C.W. Ross. 1992. Plant physiology. Wadsworth Publishing Company, Belmont, CA.

Schwartzbach, S.D. 1990. Photocontrol of organelle biogenesis in Euglena. Photochem. Photobiol. 51:231-254. 
Siefermann-Harms, D. 1987. The light-harvesting and protective functions of carotenoids in photosynthetic membranes. Physiol. Plant. 69:561-568.

Sun, J., J.N. Nishio, and T.C. Vogelmann. 1998. Green light drives CO2 fixation deep within leaves. Plant Cell Physiol. 39:1020-1026.

Taiz, L. and E. Zeiger. 1991. Plant physiology. The Benjamin/Cummings Publishings Company, Inc., Redwood City, CA.

Talbott, L.D., G. Nikolova, A. Ortiz, I. Shmayevich, and E. Zeiger. 2002. Green light reversal of blue-light-stimulated stomatal opening is found in a diversity of plant species. AJB 89:366-368.

Terashima, I., T. Fujita, T. Inoue, W.S. Chow, and R. Oguchi. 2009. Green light drives leaf photosynthesis more efficiently than red light in strong white light: Revisiting the enigmatic question of why leaves are green. Plant Cell Physiol. 50:684-697.

Vierstra, R.D. and K.L. Poff. 1981. Role of carotenoids in the phototropic response of corn seedlings. Plant Physiol. 68:798801 .

Wang, H.Y. 2010. Vertical cultivation of Boston lettuce (Lactuca sativa) production in plant factory. MS Thesis, National Taiwan Univ. Taipei.

Xu, H.L., Q. Xu, F.L. Li, Y. Feng, F. Qin, and W. Fang. 2012. Applications of xerophytophysiology in plant production-LED blue light as a stimulus improved the tomato crop. Sci. Hort. 148:190-196. 